\title{
АНАЛИЗ ВНЕКЛЕТОЧНОЙ ФРАКЦИИ РНК ПЛАЗМЫ КАК ИНСТРУМЕНТ ДИАГНОСТИКИ В ОНКОЛОГИИ
}

\author{
Е. А. Лоломадзе $\bowtie$, В. В. Кометова, В. В. Родионов
}

Национальный медицинский исследовательский центр акушерства, гинекологии и перинатологии имени В. И. Кулакова, Москва, Россия

\begin{abstract}
Одна из ключевых задач современной онкодиагностики - поиск ранних предикторов злокачественных новообразований (ЗНО) при анализе наиболее доступных видов биоматериала. Жидкостная биопсия представляет собой одну из неинвазивных методик и включает в себя обнаружение и выделение циркулирующих опухолевых клеток, циркулирующих опухолевых нуклеиновых кислот и экзосом из плазмы крови у пациентов со злокачественными заболеваниями. Множество работ посвящено исследованию внеклеточной фракции ДНК при ЗНО. Вместе с тем активную пролиферацию трансформированных клеток при развитии опухолей сопровождают значительные изменения экспрессии определенных генов. Обнаружение тканеспецифичных транскриптов в составе внеклеточной РНК плазмы крови (внРНК) позволяет предположить, что представленность циркулирующих в плазме РНК связана с развитием патологического процесса непосредственно в первичном очаге. На наш взгляд, внРНК плазмы крови представляют практическую ценность в качестве молекулярно-генетических маркеров ранней диагностики в онкологии.
\end{abstract}

Ключевые слова: циркулирующие нуклеиновые кислоты, плазма крови, циркулирующие опухолевые клетки, внРНК, микроРНК, биомаркеры, онкология Финансирование: исследование выполнено в рамках работ по Государственному заданию №АААА-А18-118053190012-9 «Разработка тест-системы для ранней диагностики рака молочной железы и рака яичников на основе анализа свободно циркулирующих (внеклеточных) РНК периферической крови".

Благодарности: мы благодарим Центр высокоточного редактирования и генетических технологий для биомедицины, Университет Пирогова (Москва, Россия) за помощь в интерпретации данных и анализе некоторых результатов.

Вкладе авторов: Е. А. Лоломадзе - анализ литературных источников и написание текста; В. В. Кометова, В. В. Родионов — написание и редактирование статьи.

$\triangle$ Для корреспонденции: Елена Анатольевна Лоломадзе ул. Опарина, 4, г. Москва, 117997; 6332424@gmail.com

Статья получена: 23.06.2020 Статья принята к печати: 26.06.2020 Опубликована онлайн: 30.06.2020

DOI: $10.24075 /$ vrgmu.2020.040

\section{CIRCULATING RNA IN BLOOD PLASMA AS DIAGNOSTIC TOOL FOR CLINICAL ONCOLOGY}

Lolomadze EA $\bowtie$, Kometova W, Rodionov W

Kulakov National Medical Research Center for Obstetrics, Gynecology and Perinatology, Moscow, Russia

One of the key challenges facing today's oncology is the discovery of early predictors of malignant neoplasms in patients' biological samples. Liquid biopsy is a noninvasive diagnostic technique based on the detection and isolation of tumor cells, tumor-derived nucleic acid and exosomes circulating in the blood plasma of cancer patients. There is a plethora of research studies of circulating tumor DNA in patients with MN. The active proliferation of tumor cells occurs in the backdrop of altered gene expression. The presence of tissue-specific transcripts in the circulating RNA fraction suggests that levels of circulating RNA reflect the development of the primary tumor. We think that cell-free RNA circulating in the blood plasma is a promising molecular biomarker for early cancer detection.

Keywords: circulating nucleic acids, blood plasma, circulating tumor cells, circulating RNA, miRNA, biomarkers, oncology

Funding: the study was conducted under the state assignment AAAA-A18-118053190012-9 (Development of assays for early diagnosis of breast and ovarian cancers based on the analysis of RNA circulating in the peripheral blood).

Acknowledgements: we thank the Center for Precision Genome Editing and Genetic Technologies for Biomedicine of Pirogov Russian National Medical Research University (Moscow, Russia) for their help in interpreting the data and analyzing some of the results.

Author contribution: Lolomadze EA — literature analysis and preparation of the manuscript draft; Kometova W, Rodionov W — editing and manuscript revision

$\triangle$ Correspondence should be addressed: Elena A. Lolomadze

Oparina, 4, Moscow, 117997; 6332424@gmail.com

Received: 23.06.2020 Accepted: 26.06.2020 Published online: 30.06.2020

DOI: 10.24075/brsmu.2020.040

Один из перспективных скрининговых подходов в онкодиагностике получил название жидкостной биопсии. Он состоит в обнаружении циркулирующих опухолевых клеток, циркулирующей опухолевой ДНК или РНК и экзосом в плазме крови у пациентов со злокачественными новообразованиями (ЗНО). Жидкостная биопсия включает различные методы анализа: количественный анализ представленности отдельных молекул, в том числе и белковых, анализ последовательности нуклеиновых кислот, анализ метилирования ДНК и др. [1]. Анализ внеклеточной фрракции нуклеиновых кислот плазмы крови дает возможность отслеживать генетическую гетерогенность опухоли в динамике (в ответ на применение различных методов лечения, подавляющих рост опухолевых клеток) $[2,3]$.

Известно, что апоптотические или некротические клетки высвобождают в кровоток фрагменты ДНК и
РНК, а также экзосомы (мембранные инкапсулированные субклеточные структуры, содержащие белки и нуклеиновые кислоты, выделяемые опухолевыми клетками) [4]. Клетки от этапа раннего онкогенеза до метастазирования в ходе эволюции опухоли накапливают специфичные мутации и эпигенетические модификации, что может быть отражено во фракции внеклеточных нуклеиновых кислот.

\section{Анализ внеклеточной фракции ДНК}

Анализ внеклеточной фракции ДНК как диагностический инструмент в онкологии используют уже более 20 лет, применяя при раках легких [5, 6], головы и шеи [7], пищевода [8], молочной железы [9], печени [10], толстой кишки [11], поджелудочной железы [12], почек [13] и др. Как правило, определяют наличие мутаций онкогенов, геновсупрессоров опухоли или микросателлитные изменения 
[6, 9, 13]. Анализ метилирования циркулирующей ДНК также может быть информативен для постановки диагноза, прогнозирования и мониторинга роста опухолей $[8,14]$. Кроме примеров с ЗНО, количественные аберрации циркулирующей ДНК описаны в исследованиях ряда других патологических состояний, включая преэклампсию [15], хромосомные анеуплоидии плода [16] и неукротимую рвоту беременных [17].

\section{Анализ внеклеточной фракции мРНК}

Поскольку активную пролиферацию опухолевых клеток и эволюцию опухоли сопровождают значительные изменения просиля представленности многих транскриптов (относительно нормы), используя количественную ОТ-ПЦР, можно попытаться детектировать изменение профиля внеклеточных мРНК [18]. Так, ОТ-ПЦР успешно применили для оценки содержания мРНК генов «домашнего хозяйства", циркулирующей в крови в норме и при опухолевой патологии [19]. Циркулирующие РНК изучали при таких ЗНО, как меланома [20-22], фолликулярная лимфома [23], рак молочной железы [22, 24-28], толстой кишки [23, 29], печени [30], пищевода [21], носоглотки [31], щитовидной железы [22], простаты [40, 41], легких [32] и др. При этом внРНК исследовали и при патологических состояниях неонкологического спектра - у пациентов с травмой [33, 34], диабетической ретинопатией [35] или у женщин во время беременности (фетальная мРНК) [36].

Так, для рака молочной железы (РМЖ) обнаружили статистически значимое изменение содержания МРНК hTERT в плазме пациентов с начальными стадиями РMЖ по сравнению со здоровыми людьми. При этом было показано, что присутствие мPHK hTERT в плазме пациентов с РMЖ зависит от хирургического удаления опухоли [25]. Однако hTERT, скорее всего, не является РМЖ-специфичным маркером, поскольку его изменение обнаружено и у пациентов с меланомой и раком щитовидной железы [22]. Экспрессия мPHK hMAM в плазме в значительной степени коррелировала с неблагоприятным прогнозом и более низкими показателями выживаемости у пациенток с РМЖ [26]. В другом исследовании продемонстрирован повышенный уровень мPHK Bmi-1 в плазме у пациентов с РМЖ в сравнении со здоровыми [27]. Недавно показано, что уровень циркулирующей МРНК большого межгенного некодирующего PHK-регулятора репрограммирования (LincRNA-ROR) может быть потенциальным биомаркером для диагностики РМЖК, и, учитывая, что его уровни в плазме снижались в послеоперационном периоде по сравнению с предоперационными образцами, данный маркер может быть использован для мониторинга состояния пациентов [28].

При раке яичников обнаружены повышенный уровень сывороточного МMP-9 у пациенток с запущенными стадиями и его корреляция с плохим прогнозом, что указывает на потенциальную прогностическую роль этого биомаркера [37]. Выявление циркулирующей внРНК HMGA2 тоже может быть инструментом для диагностики и мониторинга пациенток с раком яичников [38].

При раке предстательной железы у пациентов с метастазами наблюдают более высокие уровни циркулирующей мРНК сВМР6 в сравнении с пациентами с контролируемой локализованной опухолью. При этом для H3K27me3 характерно обратное распределение и его уровень был значительно ниже у пациентов с метастазами, чем у пациентов с более ранними стадиями. Таким образом, уровни циркулирующих в плазме крови мРНК сВМР6 и Н3К27 после лечения позволяют отличать метастатический рак предстательной железы от локализованного заболевания [39]. Количественная оценка мPHK hTERT в плазме также может быть опухолевым маркером для различения локализованного и местнораспространенного рака простаты [40].

\section{Анализ состава экзосом}

Особое внимание в последнее время уделяют изучению секретируемых опухолью внеклеточных везикул (экзосом и микровезикул), способствующих, как считается, инвазии и метастазированию [41, 42].

Внеклеточные везикулы являются специализированными мембранными органоидами, секретируемыми большинством типов клеток, и содержат различные молекулярные составляющие, включая РНК, белки, липиды и метаболиты $[43,44]$. В настоящее время внеклеточные везикулы все чаще признают важными медиаторами межклеточной коммуникации, а именно средством для транспорта мРНК через внеклеточную среду от опухолевых клеток к нормальным клеткам [45, 46].

В микровезикулах стабильно обнаруживаются микроРНК, различные виды длинных РНК (Включая мРНК), кольцевая PHK и длинные некодирующие PHK $[47,48]$. Профили РНК внеклеточных везикул здоровых людей и пациентов с гепатоцеллюлярным раком достоверно различались [48].

\section{Анализ внеклеточной фракции микроРНК}

МикроРНК представляют собой группу некодирующих регуляторных РНК, состоящих примерно из 22 нуклеотидов и играющих важную роль в регуляции экспрессии генов [49]. Они могут иметь определенные преимущества по сравнению с мРНК в качестве циркулирующих биомаркеров из-за своей высокой стабильности. Кроме упомянутой выше экзосомной фракции микроРНК, Они циркулируют и вне экзосом $[50,51]$ и стабильны, повидимому, благодаря связыванию с белками-аргонавтами [52] или липопротеиновыми комплексами (например, липопротеинами высокой плотности) [53].

Анализ циркулирующих микроРНК описан для пациентов с лимфомой [54], а также в плазме и сыворотке пациентов с раком простаты [55]. Уровень представленности miR26а в плазме может выявлять пациентов с эпителиальным раком яичников [56]. Представленность четырех микроРНК (miR-148b, miR-376c, miR-409-3p и miR-801) значительно возрастает в плазме больных РМЖ [57]. Установлено также повышение уровня микроРHK (miR-16, miR-21 и miR-451) и значительное снижение содержания miR-145 в плазме пациенток с РМЖ [58]. При этом комбинация miR145 и miR-451 была лучшим биомаркером при различении РМЖ от здорового контроля и всех других видов рака, включенных в это исследование.

\section{Проблемы и ограничения метода}

Хотя анализ внРНК имеет высокий потенциал применения в различных областях медицины, эта технология содержит и ряд недостатков. Количественную оценку внРНК затрудняют искажения, возникающие в ходе амплификации мишеней, особенно при анализе низкопредставленных молекул [59]. Искажения могут быть обусловлены и разной эффективностью метода обратной транскрипции на разных последовательностях микроРНК и мРНК при различном 
молекулярном окружении. Поэтому стратегии обнаружения ВНРНК без ПЦР представляют большой интерес [60, 61].

На сегодняшний день большинство предложенных диапностических подходов на основе анализа внРНК обладает сравнительно низкой чувствительностью и специфичностью [62]. Для повышения этих показателей необходимо проведение больших проспективных когортных исследований.

\section{ВЫВОДЫ}

Анализ внРНК при онкологических заболеваниях, на наш взгляд, демонстрирует высокую диагностическую и прогностическую ценность этого вида малоинвазивных биомаркеров. Информативность жидкостной биопсии можно повысить за счет дифференциального анализа экзосомной и свободно циркулирующей фракций ВНPHК, включая анализ микроРНК. Для снижения ложноположительных и ложноотрицательных результатов необходимо применение стандартизованных протоколов отбора проб, выделения внРНК и анализа полученных результатов. Для выбора наиболее чувствительных и специфичных панелей внРНК необходимо проведение более масштабных проспективных когортных исследований.

\section{Литература}

1. Qiu J, Xu J, Zhang K, Gu W, Nie L. Refining Cancer Management Using Integrated Liquid Biopsy. Theranostics. 2020; 10 (5): 2374 84. DOI: 10.7150/thno.40677.

2. Shen J, Kong W, Wu Y, Ren H, Wei J, Yang Y, et al. Plasma mRNA as liquid biopsy predicts chemo-sensitivity in advanced gastric cancer patients. J Cancer. 2017; 8 (3): 434-2. DOI: 10.7150/ jca.17369.

3. Perakis S, Speicher MR. Emerging concepts in liquid biopsies. BMC Med. 2017; 15 (1): 75

4. Buder A, Tomuta C, Filipits M. The potential of liquid biopsies Curr Opin Oncol. 2016; 28: 130-134.

5. Sozzi G, Conte D, Leon M, Ciricione R, Roz L, Ratcliffe C, et al. Quantification of free circulating DNA as a diagnostic marker in lung cancer. J Clin Oncol. 2003; 21: 3902-8.

6. Sozzi G, Musso K, Ratcliffe C, Goldstraw P, Pierotti MA, Pastorino U. Detection of microsatellite alterations in plasma DNA of non-small cell lung cancer patients: a prospect for early diagnosis. Clin Cancer Res. 1999. 5: 2689-92.

7. Egyud M, Sridhar P, Devaiah A, Yamada E, Saunders S, Ståhlberg A, et al. Plasma circulating tumor DNA as a potential tool for disease monitoring in head and neck cancer. Head Neck. 2019; 41 (5): 1351-8. DOI: 10.1002/hed.25563.

8. Kawakami K, Brabender J, Lord RV, Groshen S, Greenwald BD, Krasna MJ, et al. Hypermethylated APC DNA in plasma and prognosis of patients with esophageal adenocarcinoma. JNCl. 2000; 92 (22): 1805-11. Available from: https://doi.org/10.1093/ jnci/92.22.1805.

9. Shaw JA, Smith BA, Walsh T, Johnson S, Primrose L, Slade MJ. Microsatellite alterations plasma DNA of primary breast cancer patients. Clin Cancer Res. 2000; 6: 1119-24.

10. Kirk GD, Camus-Randon AM, Mendy M, Goedert JJ, Merle P, Trepo C, et al. Ser-249 p53 mutations in plasma DNA of patients with hepatocellular carcinoma from the Gambia. J Natl Cancer Inst (Bethesda). 2000; 92 (2): 148-53. DOI: 10.1093/jnci/92.2.148.

11. Koprenski MS, Benko FA, Borys DJ, Khan A, McGarrity TJ, Gocke C. D. Somatic mutation screening: identification of individuals harboring K-ras mutations with the use of plasma DNA. J Natl Cancer Inst (Bethesda). 2000; 92: 918-23.

12. Yamada T, Nakamori S, Ohzato H, Oshima S, Aoki T, Higaki N. Detection of K-ras gene mutations in plasma DNA of patients with pancreatic adenocarcinoma: correlation with clinicopathological features. Clin Cancer Res. 1998; 4: 1527-32.

13. Goessl C, Heicappell R, Muncher R, Anker P, Stroun M, Krause H, et al. Microsatellite analysis of plasma DNA from patients with clear cell renal carcinoma. Cancer Res. 1998; 58: 4728-32.

14. Bryzgunova OE, Laktionov PP. Current methods of extracellular DNA methylation analysis. Molecular Biology. 2017; 51 (2): 16783 DOI: 10.1134/S0026893317010071.

15. Zhong XY, Laivuori H, Livingston JC, Ylikorkala O, Sibai BM, Holzgreve W, et al. Elevation of both maternal and fetal extracellular circulating deoxyribonucleic acid concentrations in the plasma of pregnant women with preeclampsia. Am J Obstet Gynecol. 2001; 184 (3): 414-9. DOI: 10.1067/mob.2001.109594.

16. Zhong XY, Burk MR, Troeger C, Jackson LR, Holzgreve W, Hahn S. Fetal DNA in maternal plasma is elevated in pregnancies with aneuploid fetuses. Prenatal Diagn. 2000; 20 (10): 795-8.

17. Sekizawa A, Sugito Y, Iwasaki M, Watanabe A, Jimbo M, Hoshi S, et al. Cell-free fetal DNA is increased in plasma of women with hyperemesis gravidarum. Clin Chem. 2001; 47 (12): 2164-5.

18. Tong Y, Lo YM. Diagnostic developments involving cell-free (circulating) nucleic acids. Clin Chim Acta. 2006; 363: 187-96.

19. Pachot A, Blond J-L, Mougin B, Miossec P. Peptidylpropyl isomerase $B$ (PPIB): a suitable reference gene for mRNA quantification in peripheral whole blood. Biotechnol. 2004; 114 (1-2): 121-4. DOI: 10.1016/j.jbiotec.2004.07.001.

20. Hasselmann DO, Rappl G, Rossler M, Ugurel S, Tilgen W, Reinhold $U$. Detection of tumor-associated circulating mRNA in serum, plasma and blood cells from patients with disseminated malignant melanoma. Oncol Rep. 2001; 8 (1): 115-8. DOI: 10.3892/or.8.1.115.

21. El-Hefnawy T, Raja S, Kelly L, Bigbee WL, Kirkwood JM, Luketich $J D$, et al. Characterization of amplifiable, circulating RNA in plasma and its potential as a tool for cancer diagnostics. Clin Chem. 2004; 50: 564-73. DOI: 10.1373/clinchem.2003.028506.

22. Novakovic S, Hocevar M, Zgajnar J, Besic N, Stegel V. Detection of telomerase RNA in the plasma of patients with breast cancer, malignant melanoma or thyroid cancer. Oncology Reports. 2004; 11 (1): 245-52. DOI: 10.3892/or.11.1.245.

23. Dasi F, Lledo S, Garcia-Granero E, Ripoll R, Marugan M, Tormo M, et al. Real-time quantification in plasma of human telomerase reverse transcriptase (hTERT) mRNA: a simple blood test to monitor disease in cancer patients. Lab Invest. 2001; 81 (5): $767-$ 9. DOI: 10.1038/ labinvest.3780285.

24. Silva JM, Dominguez G, Silva J, Garcia JM, Sanchez A, Rodriguez O, et al. Detection of epithelial messenger RNA in the plasma of breast cancer patients is associated with poor prognosis tumor characteristics. Clin Cancer Res. 2001; 7 (9): 2821-5.

25. Perhavec A, Cerkovnik P, Novakovic S, Zgajnar J. The hTERT mRNA in plasma samples of early breast cancer patients, non-cancer patients and healthy individuals. Neoplasma. 2008; 55: 549-54.

26. Lee G-W, Kim J-Y, Koh E-H, Kang D, Choi DS, Maeng K-Y, et al. Plasma human mammaglobin mRNA associated with poor outcome in patients with breast cancer. Genet Mol Res. 2012; 11 (4): 4034-42. DOI: 10.4238/2012.November.28.2.

27. Silva J, García V, García JM, Peña C, Domínguez G, Díaz R, et al. Circulating Bmi-1 mRNA as a possible prognostic factor for advanced breast cancer patients. Breast Cancer Research. 2007; 9: R55.

28. Zhang K, Luo Z, Zhang Y, Wang Y, Cui M, Liu L, et al. Detection and Analysis of circulating large intergenic non-coding RNA regulator of reprogramming in plasma for breast cancer. Thorac Cancer. 2018; 9 (1): 66-74. DOI: 10.1111/1759-7714.12537.

29. Wong SC, Lo SF, Cheung MT, Ng KO, Tse CW, Lai BS, et al. Quantification of plasma beta-catenin mRNA in colorectal cancer and adenoma patients. Clin Cancer Res. 2004; 10 (5): 1613-7.

30. Abdelghany AM, Rezk NS, Osman MM, Hamid Al, Al-Breedy AM, 
Abdelsattar HA. Using Lamin B1 mRNA for the early diagnosis of hepatocellular carcinoma: a cross-sectional diagnostic accuracy study. F1000Res. 2018; 7: 1339. DOI: 10.12688/ f1000research.14795.1.

31. Fu X, Shen C, Li G, Zhang X, Wen Z. Quantitative detection of plasma level of human telomerase reverse transcriptase mRNA in patients with nasopharyngeal carcinoma. Journal of Southern Medical University. 2015; 35 (6): 894-7.

32. Leng Q, Tsou J-H, Zhan M, Jiang F. Fucosylation Genes as Circulating Biomarkers for Lung Cancer. J Cancer Res Clin Oncol. 2018; 144 (11): 2109-15. DOI: 10.1007/s00432-018-2735-0.

33. Rainer TH, Lam NY, Tsui NB, Ng EK, Chiu RW, Joynt GM, et al. Effects of filtration on glyceraldehyde-3-phosphate dehydrogenase mRNA in the plasma of trauma patients and healthy individuals. Clin Chem. 2004; 50 (1): 206-8. DOI: 10.1373/ clinchem.2003.022533.

34. Atamaniuk J, Vidotto C, Tschan $\mathrm{H}$, et al. Increased concentrations of cell-free plasma DNA after exhaustive exercise. Clin Chem. 2004; 50: 1668-70.

35. Hamaoui K, Butt A, Powrie J, Swaminathan R. Realtime quantitative PCR measurement of circulatory rhodopsin mRNA in healthy subjects and patients with diabetic retinopathy. Ann N Y Acad Sci. 2004; 1022: 152-6. DOI: 10.1196 / annals.1318.025.

36. Tsui NB, Chim SS, Chiu RW, Lau TK, Ng EK, Leung TN, et al. Systematic micro-array based identification of placental mRNA in maternal plasma: towards non-invasive prenatal gene expression profiling. J Med Genet. 2004; 41: 461-7. DOI: 10.1136/ jmg.2003.016881.

37. HuX, LiD, Zhang W, Zhou J, Tang B, Li L. Matrix metalloproteinase-9 expression correlates with prognosis and involved in ovarian cancer cell invasion. Archives of Gynecology and Obstetrics. 2012; 286 (6): 1537-43. DOI: 10.1007/s00404-012-2456-6.

38. Galdiero F, Romano A, Pasquinelli R, Pignata S, Greggi S, Vuttariello $E$, et al. Detection of high mobility group A2 specific mRNA in the plasma of patients affected by epithelial ovarian cancer. Oncotarget. 2015; 6 (22): 19328-35. DOI: 10.18632/ oncotarget.2896.

39. Deligezer U, Yaman F, Darendeliler E, Dizdar Y, Holdenrieder S, Kovancilar M, et al. Post-treatment circulating plasma BMP6 mRNA and H3K27 methylation levels discriminate metastatic prostate cancer from localized disease. Clinica Chimica Acta. 2010; 411 (19-20): 1452-6. DOI: 10.1016/j.cca.2010.05.040.

40. March-Villalba JA, Martínez-Jabaloyas JM, Herrero MJ, Santamaría J, Aliño SF, Dasí F. Plasma hTERT mRNA discriminates between clinically localized and locally advanced disease and is a predictor of recurrence in prostate cancer patients. Expert Opin Biol Ther. 2012; 12: 69-77. DOI: 10.1517/14712598.2012.685716.

41. Peinado $\mathrm{H}$, et al. Melanoma exosomes educate bone marrow progenitor cells toward a pro-metastatic phenotype through MET. Nat Med. 2012; 18: 883-91.

42. Hoshino A, Costa-Silva B, Shen T-L, Rodrigues G, Hashimoto A Mark MT, et al. Tumour exosome integrins determine organotropic metastasis. Nature. 2015; 527 (7578): 329-35. DOI: 10.1038/ nature15756

43. Colombo M, Raposo G, Thery C. Biogenesis, secretion, and intercellular interactions of exosomes and other extracellular vesicles. Annu Rev Cell Dev Biol. 2014; 30: 255-89. DOI: 10.1146/annurev-cellbio-101512-122326.

44. van Niel G, D'Angelo G, Raposo G. Shedding light on the cell biology of extracellular vesicles. Nat Rev Mol Cell Biol. 2018; 19 (4): 213-28. DOI: 10.1038/nrm.2017.125.

45. Shah R, Patel T, Freedman JE. Circulating extracellular vesicles in human disease. N Engl J Med. 2018; 379 (10): 958-66. DOI:
10.1056/NEJMra1704286.

46. Valadi H, Ekstrom K, Bossios A, Sjostrand M, Lee JJ, Lotvall JO. Exosome-mediated transfer of mRNAs and microRNAs is a novel mechanism of genetic exchange between cells. Na Cell Biol. 2007; 9 (6): 654-59. DOI: 10.1038/ncb1596.

47. Zhang J, Li S, Li L, Li M, Guo C, Yao J, Mi S. Exosome and exosomal microRNA: trafficking, sorting, and function. Genomics Proteomics Bioinformatics. 2015; 13 (1): 17-24. DOI: 10.1016/j. gpb.2015.02.001

48. Li Y, Zhao J, Yu S, Wang Z, He X, Su Y, et al. Extracellular Vesicles Long RNA Sequencing reveals abundant mRNA, circRNA, and IncRNA in human blood as potential biomarkers for cancer diagnosis. Clin Chem. 2019; 65 (6): 798-808. DOI: 10.1373/ clinchem.2018.301291.

49. Bartel DP. MicroRNAs: genomics, biogenesis, mechanism, and function. Cell. 2004; 116 (2): 281-97. DOI: 10.1016/S00928674(04)00045-5.

50. Weber JA, Baxter DH, Zhang S, Huang DY, Huang KH, Lee MJ, et al. The microRNA spectrum in 12 body fluids. Clin Chem. 2010; 56 (11): 1733-41. DOI: 10.1373/clinchem.2010.147405.

51. Boon RA, Vickers KC. Intercellular transport of microRNAs. Arterioscler Thromb Vasc Biol. 2013; 33 (2): 186-92. DOI: 10.1161/ATVBAHA.112.300139.

52. Arroyo JD, Chevillet JR, Kroh EM, Ruf IK, Pritchard CC, Gibson DF, et al. Argonaute2 complexes carry a population of circulating microRNAs independent of vesicles in human plasma. Proc Natl Acad Sci USA. 2011; 108 (12): 5003-8. DOI: 10.1073/ pnas. 1019055108 .

53. Vickers KC, Palmisano BT, Shoucri BM, Shamburek RD, Remaley AT. MicroRNAs are transported in plasma and delivered to recipient cells by high-density lipoproteins. Nat. Cell Biol. 2011; 13: 42333. DOI: $10.1038 / \mathrm{ncb} 2210$.

54. Van Eijndhoven MA, Zijlstra JM, Groenewegen NJ, Drees EE, van Niele S, Baglio SR, et al. Plasma vesicle miRNAs for therapy response monitoring in Hodgkin lymphoma patients. JCl Insight. 2016; 1 (19): e89631. DOI: 10.1172/jci.insight.89631.

55. Watahiki A, Macfarlane RJ, Gleave ME, Crea F, Wang Y, Helgason CD, et al. Plasma miRNAs as biomarkers to identify patients with castration-resistant metastatic prostate cancer. Int J Mol Sci. 2013; 14 (4): 7757-70. DOI: 10.3390/ijms14047757.

56. Shen W, Song M, Liu J, Qiu G, Li T, Hu Y, et al. MiR-26a Promotes Ovarian Cancer Proliferation and Tumorigenesis. PLoS One. 2014; 9 (1): e86871. DOI: 10.1371/journal.pone.0086871.

57. CukK, Zucknick M, Heil J, Madhavan D, Schott S, Turchinovich A, et al. Circulating microRNAs in plasma as early detection markers for breast cancer. International Journal of Cancer. 2013; 132 (7): 1602-12. Available from: https://DOI.org/10.1002/ijc.27799.

58. NgEK, Li R, Shin VY, Jin HC, Leung CP, MaES, et al. Circulating microRNAs as specific biomarkers for breast cancer detection. PLoS One. 2013; 8 (1). DOI: 10.1371/journal.pone.0053141.

59. Müllauer L. Next generation sequencing: Clinical applications in solid tumours. Memo. 2017; 10 (4): 244-7. DOI: 10.1007/ s12254-017-0361-1.

60. Giuffrida MC, Spoto G. Integration of isothermal amplification methods in microfluidic devices: Recent advances. Biosens Bioelectron. 2017; 90: 174-86. DOI: 10.1016/j.bios.2016.11.045.

61. Giuffrida MC, Zanoli LM, D'Agata R, Finotti A, Gambari R, Spoto G. Isothermal circular-strand-displacement polymerization of DNA and microRNA in digital microfluidic devices. Anal Bioanal Chem. 2015; 407 (6): 1533-43. DOI: 10.1007/s00216-014-8405-4.

62. Alix-Panabieres C, Pantel K. Challenges in circulating tumour cell research. Nat Rev Cancer. 2014; 14 (9): 623-31. DOl: 10.1038/ nrc3820.

\section{References}

1. Qiu J, Xu J, Zhang K, Gu W, Nie L. Refining Cancer Management Using Integrated Liquid Biopsy. Theranostics. 2020; 10 (5): 2374 84. DOI: 10.7150/thno.40677.

2. Shen J, Kong W, Wu Y, Ren H, Wei J, Yang Y, et al. Plasma mRNA as liquid biopsy predicts chemo-sensitivity in advanced gastric

cancer patients. J Cancer. 2017; 8 (3): 434-2. DOI: 10.7150/ jca.17369.

3. Perakis S, Speicher MR. Emerging concepts in liquid biopsies. BMC Med. 2017; 15 (1): 75.

4. Buder A, Tomuta C, Filipits M. The potential of liquid biopsies. 
Curr Opin Oncol. 2016; 28: 130-134.

5. Sozzi G, Conte D, Leon M, Ciricione R, Roz L, Ratcliffe C, et al. Quantification of free circulating DNA as a diagnostic marker in lung cancer. J Clin Oncol. 2003; 21: 3902-8.

6. Sozzi G, Musso K, Ratcliffe C, Goldstraw P, Pierotti MA, Pastorino U. Detection of microsatellite alterations in plasma DNA of non-small cell lung cancer patients: a prospect for early diagnosis. Clin Cancer Res. 1999. 5: 2689-92.

7. Egyud M, Sridhar P, Devaiah A, Yamada E, Saunders S, Ståhlberg A, et al. Plasma circulating tumor DNA as a potential tool for disease monitoring in head and neck cancer. Head Neck. 2019; 41 (5): 1351-8. DOI: 10.1002/hed.25563.

8. Kawakami K, Brabender J, Lord RV, Groshen S, Greenwald BD, Krasna MJ, et al. Hypermethylated APC DNA in plasma and prognosis of patients with esophageal adenocarcinoma. JNCl. 2000; 92 (22): 1805-11. Available from: https://doi.org/10.1093/ jnci/92.22.1805

9. Shaw JA, Smith BA, Walsh T, Johnson S, Primrose L, Slade MJ. Microsatellite alterations plasma DNA of primary breast cancer patients. Clin Cancer Res. 2000; 6: 1119-24.

10. Kirk GD, Camus-Randon AM, Mendy M, Goedert JJ, Merle P, Trepo C, et al. Ser-249 p53 mutations in plasma DNA of patients with hepatocellular carcinoma from the Gambia. J Natl Cancer Inst (Bethesda). 2000; 92 (2): 148-53. DOI: 10.1093/jnci/92.2.148.

11. Koprenski MS, Benko FA, Borys DJ, Khan A, McGarrity TJ, Gocke C. D. Somatic mutation screening: identification of individuals harboring K-ras mutations with the use of plasma DNA. J Natl Cancer Inst (Bethesda). 2000; 92: 918-23.

12. Yamada T, Nakamori S, Ohzato H, Oshima S, Aoki T, Higaki N. Detection of K-ras gene mutations in plasma DNA of patients with pancreatic adenocarcinoma: correlation with clinicopathological features. Clin Cancer Res. 1998; 4: 1527-32.

13. Goessl C, Heicappell R, Muncher R, Anker P, Stroun M, Krause H, et al. Microsatellite analysis of plasma DNA from patients with clear cell renal carcinoma. Cancer Res. 1998; 58: 4728-32.

14. Bryzgunova OE, Laktionov PP. Current methods of extracellular DNA methylation analysis. Molecular Biology. 2017; 51 (2): 16783 DOI: 10.1134/S0026893317010071.

15. Zhong XY, Laivuori H, Livingston JC, Ylikorkala O, Sibai BM, Holzgreve W, et al. Elevation of both maternal and fetal extracellular circulating deoxyribonucleic acid concentrations in the plasma of pregnant women with preeclampsia. Am J Obstet Gynecol. 2001 184 (3): 414-9. DOI: 10.1067/mob.2001.109594.

16. Zhong XY, Burk MR, Troeger C, Jackson LR, Holzgreve W, Hahn S. Fetal DNA in maternal plasma is elevated in pregnancies with aneuploid fetuses. Prenatal Diagn. 2000; 20 (10): 795-8.

17. Sekizawa A, Sugito Y, Iwasaki M, Watanabe A, Jimbo M, Hoshi S, et al. Cell-free fetal DNA is increased in plasma of women with hyperemesis gravidarum. Clin Chem. 2001; 47 (12): 2164-5.

18. Tong Y, Lo YM. Diagnostic developments involving cell-free (circulating) nucleic acids. Clin Chim Acta. 2006; 363: 187-96.

19. Pachot A, Blond J-L, Mougin B, Miossec P. Peptidylpropyl isomerase B (PPIB): a suitable reference gene for mRNA quantification in peripheral whole blood. Biotechnol. 2004; 114 (1-2): 121-4. DOI: 10.1016/j.jbiotec.2004.07.001.

20. Hasselmann DO, Rappl G, Rossler M, Ugurel S, Tilgen W, Reinhold U. Detection of tumor-associated circulating mRNA in serum, plasma and blood cells from patients with disseminated malignant melanoma. Oncol Rep. 2001; 8 (1): 115-8. DOI: 10.3892/or.8.1.115.

21. El-Hefnawy T, Raja S, Kelly L, Bigbee WL, Kirkwood JM, Luketich $\mathrm{JD}$, et al. Characterization of amplifiable, circulating RNA in plasma and its potential as a tool for cancer diagnostics. Clin Chem. 2004; 50: 564-73. DOI: 10.1373/clinchem.2003.028506.

22. Novakovic S, Hocevar M, Zgajnar J, Besic N, Stegel V. Detection of telomerase RNA in the plasma of patients with breast cancer, malignant melanoma or thyroid cancer. Oncology Reports. 2004; 11 (1): 245-52. DOI: 10.3892/or.11.1.245.

23. Dasi F, Lledo S, Garcia-Granero E, Ripoll R, Marugan M, Tormo M, et al. Real-time quantification in plasma of human telomerase reverse transcriptase (hTERT) mRNA: a simple blood test to monitor disease in cancer patients. Lab Invest. 2001; 81 (5): $767-$ 9. DOI: 10.1038/ labinvest.3780285.
24. Silva JM, Dominguez G, Silva J, Garcia JM, Sanchez A, Rodriguez O, et al. Detection of epithelial messenger RNA in the plasma of breast cancer patients is associated with poor prognosis tumor characteristics. Clin Cancer Res. 2001; 7 (9): 2821-5.

25. Perhavec A, Cerkovnik P, Novakovic S, Zgajnar J. The hTERT mRNA in plasma samples of early breast cancer patients, non-cancer patients and healthy individuals. Neoplasma. 2008; 55: 549-54.

26. Lee G-W, Kim J-Y, Koh E-H, Kang D, Choi DS, Maeng K-Y, et al. Plasma human mammaglobin mRNA associated with poor outcome in patients with breast cancer. Genet Mol Res. 2012; 11 (4): 4034-42. DOI: 10.4238/2012.November.28.2.

27. Silva J, García V, García JM, Peña C, Domínguez G, Díaz R, et al. Circulating Bmi-1 mRNA as a possible prognostic factor for advanced breast cancer patients. Breast Cancer Research. 2007; 9: $R 55$.

28. Zhang $\mathrm{K}$, Luo Z, Zhang Y, Wang Y, Cui M, Liu L, et al. Detection and Analysis of circulating large intergenic non-coding RNA regulator of reprogramming in plasma for breast cancer. Thorac Cancer. 2018; 9 (1): 66-74. DOI: 10.1111/1759-7714.12537.

29. Wong SC, Lo SF, Cheung MT, Ng KO, Tse CW, Lai BS, et al. Quantification of plasma beta-catenin mRNA in colorectal cancer and adenoma patients. Clin Cancer Res. 2004; 10 (5): 1613-7.

30. Abdelghany AM, Rezk NS, Osman MM, Hamid Al, Al-Breedy AM, Abdelsattar HA. Using Lamin B1 mRNA for the early diagnosis of hepatocellular carcinoma: a cross-sectional diagnostic accuracy study. F1000Res. 2018; 7: 1339. DOI: 10.12688/ f1000research.14795.1.

31. Fu X, Shen C, Li G, Zhang X, Wen Z. Quantitative detection of plasma level of human telomerase reverse transcriptase mRNA in patients with nasopharyngeal carcinoma. Journal of Southern Medical University. 2015; 35 (6): 894-7.

32. Leng $\mathrm{Q}$, Tsou J-H, Zhan M, Jiang F. Fucosylation Genes as Circulating Biomarkers for Lung Cancer. J Cancer Res Clin Oncol. 2018; 144 (11): 2109-15. DOI: 10.1007/s00432-018-2735-0.

33. Rainer TH, Lam NY, Tsui NB, Ng EK, Chiu RW, Joynt GM, et al. Effects of filtration on glyceraldehyde-3-phosphate dehydrogenase mRNA in the plasma of trauma patients and healthy individuals. Clin Chem. 2004; 50 (1): 206-8. DOl: 10.1373/ clinchem.2003.022533.

34. Atamaniuk J, Vidotto C, Tschan $\mathrm{H}$, et al. Increased concentrations of cell-free plasma DNA after exhaustive exercise. Clin Chem. 2004; 50: 1668-70.

35. Hamaoui K, Butt A, Powrie J, Swaminathan R. Realtime quantitative PCR measurement of circulatory rhodopsin mRNA in healthy subjects and patients with diabetic retinopathy. Ann N Y Acad Sci. 2004; 1022: 152-6. DOI: 10.1196 / annals.1318.025.

36. Tsui NB, Chim SS, Chiu RW, Lau TK, Ng EK, Leung TN, et al. Systematic micro-array based identification of placental mRNA in maternal plasma: towards non-invasive prenatal gene expression profiling. J Med Genet. 2004; 41: 461-7. DOI: 10.1136/ jmg.2003.016881.

37. HuX, LiD, Zhang W, Zhou J, Tang B, Li L. Matrix metalloproteinase-9 expression correlates with prognosis and involved in ovarian cancer cell invasion. Archives of Gynecology and Obstetrics. 2012; 286 (6): 1537-43. DOI: 10.1007/s00404-012-2456-6.

38. Galdiero F, Romano A, Pasquinelli R, Pignata S, Greggi S, Vuttariello $E$, et al. Detection of high mobility group A2 specific mRNA in the plasma of patients affected by epithelial ovarian cancer. Oncotarget. 2015; 6 (22): 19328-35. DOI: 10.18632/ oncotarget.2896.

39. Deligezer U, Yaman F, Darendeliler E, Dizdar Y, Holdenrieder S, Kovancilar M, et al. Post-treatment circulating plasma BMP6 mRNA and H3K27 methylation levels discriminate metastatic prostate cancer from localized disease. Clinica Chimica Acta. 2010; 411 (19-20): 1452-6. DOI: 10.1016/..cca.2010.05.040.

40. March-Villalba JA, Martínez-Jabaloyas JM, Herrero MJ, Santamaría J, Aliño SF, Dasí F. Plasma hTERT mRNA discriminates between clinically localized and locally advanced disease and is a predictor of recurrence in prostate cancer patients. Expert Opin Biol Ther. 2012; 12: 69-77. DOI: 10.1517/14712598.2012.685716.

41. Peinado $\mathrm{H}$, et al. Melanoma exosomes educate bone marrow progenitor cells toward a pro-metastatic phenotype through MET. Nat Med. 2012; 18: 883-91. 
42. Hoshino A, Costa-Silva B, Shen T-L, Rodrigues G, Hashimoto A, Mark MT, et al. Tumour exosome integrins determine organotropic metastasis. Nature. 2015; 527 (7578): 329-35. DOI: 10.1038/ nature15756.

43. Colombo M, Raposo G, Thery C. Biogenesis, secretion, and intercellular interactions of exosomes and other extracellular vesicles. Annu Rev Cell Dev Biol. 2014; 30: 255-89. DOl: 10.1146/annurev-cellbio-101512-122326.

44. van Niel G, D’Angelo G, Raposo G. Shedding light on the cell biology of extracellular vesicles. Nat Rev Mol Cell Biol. 2018; 19 (4): 213-28. DOI: 10.1038/nrm.2017.125.

45. Shah R, Patel T, Freedman JE. Circulating extracellular vesicles in human disease. N Engl J Med. 2018; 379 (10): 958-66. DOI: 10.1056/NEJMra1704286.

46. Valadi H, Ekstrom K, Bossios A, Sjostrand M, Lee JJ, Lotvall JO. Exosome-mediated transfer of mRNAs and microRNAs is a novel mechanism of genetic exchange between cells. Na Cell Biol. 2007; 9 (6): 654-59. DOI: 10.1038/ncb1596.

47. Zhang J, Li S, Li L, Li M, Guo C, Yao J, Mi S. Exosome and exosomal microRNA: trafficking, sorting, and function. Genomics Proteomics Bioinformatics. 2015; 13 (1): 17-24. DOl: 10.1016/j. gpb.2015.02.001.

48. Li Y, Zhao J, Yu S, Wang Z, He X, Su Y, et al. Extracellular Vesicles Long RNA Sequencing reveals abundant mRNA, circRNA, and IncRNA in human blood as potential biomarkers for cancer diagnosis. Clin Chem. 2019; 65 (6): 798-808. DOI: 10.1373/ clinchem.2018.301291.

49. Bartel DP. MicroRNAs: genomics, biogenesis, mechanism, and function. Cell. 2004; 116 (2): 281-97. DOI: 10.1016/S00928674(04)00045-5.

50. Weber JA, Baxter DH, Zhang S, Huang DY, Huang KH, Lee MJ, et al. The microRNA spectrum in 12 body fluids. Clin Chem. 2010; 56 (11): 1733-41. DOI: 10.1373/clinchem.2010.147405.

51. Boon RA, Vickers KC. Intercellular transport of microRNAs. Arterioscler Thromb Vasc Biol. 2013; 33 (2): 186-92. DOl: 10.1161/ATVBAHA.112.300139.

52. Arroyo JD, Chevillet JR, Kroh EM, Ruf IK, Pritchard CC, Gibson DF, et al. Argonaute2 complexes carry a population of circulating
microRNAs independent of vesicles in human plasma. Proc Natl Acad Sci USA. 2011; 108 (12): 5003-8. DOI: 10.1073/ pnas. 1019055108.

53. Vickers KC, Palmisano BT, Shoucri BM, Shamburek RD, Remaley AT. MicroRNAs are transported in plasma and delivered to recipient cells by high-density lipoproteins. Nat. Cell Biol. 2011; 13: 42333. DOl: 10.1038/ncb2210.

54. Van Eijndhoven MA, Zijlstra JM, Groenewegen NJ, Drees EE, van Niele S, Baglio SR, et al. Plasma vesicle miRNAs for therapy response monitoring in Hodgkin lymphoma patients. JCl Insight. 2016; 1 (19): e89631. DOI: 10.1172/jci.insight.89631.

55. Watahiki A, Macfarlane RJ, Gleave ME, Crea F, Wang Y, Helgason CD, et al. Plasma miRNAs as biomarkers to identify patients with castration-resistant metastatic prostate cancer. Int J Mol Sci. 2013; 14 (4): 7757-70. DOI: 10.3390/ijms14047757.

56. Shen W, Song M, Liu J, Qiu G, Li T, Hu Y, et al. MiR-26a Promotes Ovarian Cancer Proliferation and Tumorigenesis. PLoS One. 2014; 9 (1): e86871. DOI: 10.1371/journal.pone.0086871.

57. Cuk K, Zucknick M, Heil J, Madhavan D, Schott S, Turchinovich A et al. Circulating microRNAs in plasma as early detection markers for breast cancer. International Journal of Cancer. 2013; 132 (7): 1602-12. Available from: https://DOI.org/10.1002/ijc.27799.

58. Ng EK, Li R, Shin VY, Jin HC, Leung CP, Ma ES, et al. Circulating microRNAs as specific biomarkers for breast cancer detection. PLoS One. 2013; 8 (1). DOI: 10.1371/journal.pone.0053141.

59. Müllauer L. Next generation sequencing: Clinical applications in solid tumours. Memo. 2017; 10 (4): 244-7. DOI: 10.1007/ s12254-017-0361-1.

60. Giuffrida MC, Spoto G. Integration of isothermal amplification methods in microfluidic devices: Recent advances. Biosens Bioelectron. 2017; 90: 174-86. DOI: 10.1016/j.bios.2016.11.045.

61. Giuffrida MC, Zanoli LM, D'Agata R, Finotti A, Gambari R, Spoto G. Isothermal circular-strand-displacement polymerization of DNA and microRNA in digital microfluidic devices. Anal Bioanal Chem. 2015; 407 (6): 1533-43. DOI: 10.1007/s00216-014-8405-4.

62. Alix-Panabieres $\mathrm{C}$, Pantel K. Challenges in circulating tumour cell research. Nat Rev Cancer. 2014; 14 (9): 623-31. DOI: 10.1038/ nrc3820. 